\title{
La evaluación en la tradición educativa colombiana. Instrumento de clasificación social
}

\author{
José Guillermo Ortiz ${ }^{1}$ \\ Hernán Buitrago ${ }^{2}$
}

Recibido: 13-02-2017

Aceptado: 05-04-2017

\section{RESUMEN}

La evaluación es la punta de lanza de la calidad de la educación. El éxito educativo se mide por medio de pruebas nacionales e internacionales que aportan un valor a ciertos indicadores que son asumidos como manifestaciones de competencias desarrolladas en los educandos. La evaluación puede ser pensada en términos de su finalidad. Es un instrumento de poder que permite clasificar y seleccionar socialmente a quienes en una visión darwinista son los más aptos en un determinado modelo de persona educada para los fines que persigan quienes ejercen el poder a nivel institucional y privado. La evaluación es parte transversal de la educación y un medio para el desarrollo de autonomía.

Palabras clave: evaluación educativa, finalidad, clasificación social, selección social. 


\title{
Evaluation in the Colombian educational tradition. Social classification tool
}

\begin{abstract}
Evaluation is the spearhead of the quality of education. Educational success is measured through national and international tests that provide a value to certain indicators that are taken as manifestations of competencies developed in the learners. The evaluation can be thought of in terms of its purpose. It is an instrument of power that allows you to sort and select socially who in a Darwinian vision are more suitable in a certain model of educated person for purposes that pursue those who wield the power to institutional and private. Evaluation is the transverse part of education and a means for the development of autonomy.
\end{abstract}

Keywords: Educational evaluation; purpose; social classification; social selection.

\section{Introducción}

Este artículo es una aproximación a los marcos desde dónde se ha reflexionado sobre la evaluación educativa. Si bien la evaluación ha sido siempre parte del proceso educativo formal, su protagonismo como objeto de estudio es de reciente atención en Colombia. Las últimas dos décadas han sido particularmente prolíficas en publicaciones y se han creado grupos de investigación que han abierto líneas de desarrollo epistemológico y metodológico en las facultades de educación (Marín, 2012).

La evaluación educativa está articulada con dos procesos: el primero, la clasificación social; el segundo, la selección de grupos sociales producto de la aplicación y procesamiento de resultados de instrumentos o pruebas. La clave del planteamiento está en diferenciar, describir características y conceptualizar en torno a la especificación necesaria para definir con argumentos en contexto, entre clasificación social y selección social. 
La clasificación social es un rasgo distintivo de culturas tradicionales, tal y como las definió Max Weber, y ha sido asumida como una idea fuerte en las ciencias sociales según Mitzman (1969). Son tradicionales las culturas que orientan la movilidad social de acuerdo con criterios patrimoniales, la herencia, los abolengos, la raza, la posición socioeconómica.

La selección social es una construcción de la modernidad en la etapa de la sociedad industrial avanzada, corresponde a la forma política de los Estados nacionales. Consiste en posicionar el valor de la meritocracia, antes que el patrimonial, como mecanismo de movilidad social.

Esta diferencia en Colombia es yuxtapuesta, porque históricamente en el país han convivido en su heterogeneidad histórica, su diversidad étnica y su multiculturalidad elementos y factores que son característicos tanto de las sociedades tradicionales como de las sociedades modernas, urbanas e industrializadas. Históricamente se impuso un modelo social excluyente para la población en general, dando sustento a una oligarquía poderosa que aún conserva el control sobre las tierras productivas, la política y el Estado, la contratación pública; y ha desarrollado tanto una industria dependiente de bienes de capital, técnicas y tecnologías, como un sector de servicios apalancado en la inversión extranjera.

Tal característica muestra que en Colombia se han dado dos fenómenos que explican sus contradicciones, la marginación, la violencia, el desarrollo desigual. Se han incorporado teorías que son emblemáticas de la modernidad, pero se han mantenido prácticas tradicionales. Ha convivido el orden y la violencia. Se ha creado una disyunción entre la teoría y la práctica, se puede ser un gran teórico de la ética y de la moral y tener prácticas inmorales. Se puede tratar los logros científicos foráneos, enseñarlos, discutirlos, abrir debates sobre sus objetos y métodos, pero al mismo tiempo tener niveles muy bajos de investigación, de producción científica.

La evaluación educativa llegó al país con los primeros intentos de los gobiernos de crear una instrucción pública que contribuyera a integrar la economía nacional con la economía internacional. Proceso que no estuvo desligado del propósito de lograr la paz después de las guerras civiles del siglo XIX y de la Guerra de los Mil Días, (1899-1902), con la que el país finalizó el siglo XIX y dio inició al siglo XX. 
La realidad social y económica de un modelo de desarrollo excluyente y centralista, la concentración de la población en la región Andina, la geografía de regiones es también cultura diversa de regiones. La periferia como Chocó, la Amazonía, San Andrés, fueron y aún los son. Una otredad frente la hegemonía del centro del país tuvo un impacto en la evaluación educativa. Tanto la educación como la evaluación se desarrollaron para afianzar saberes modernos y al mismo tiempo favorecer acciones y valores basados en criterios patrimoniales.

La evaluación educativa se filtró desde los intereses de sectores dominantes, locual les permitió utilizarla en marcos de políticas educativas acordes con sus expectativas de clasificación y control. De esta manera, la apropiación de la evaluación educativa reforzó las clasificaciones sociales provenientes desde la sociedad colonial. La misma lógica de clasificar para segregar, con mecanismos y ejemplos diferentes para la Colonia, que justificaba que en una procesión religiosa los principales fueran encabezando el desfile y los mestizos, indios y negros atrás. Han afianzado durante el periodo republicano y el presente, que sea una minoría privilegiada la que puede ingresar a la universidad, en tanto la mayoría de los jóvenes no tiene acceso a la educación superior.

Académicamente se construyó un discurso mimético, -concepto desarrollado en el siglo XIX por el sociólogo Tarde (2011)-. A partir de las teorías de moda en Europa, y mediante argumentos científicos, se generó una visión de país y de su composición demográfica, donde la etnia blanca y mestiza blanca prevaleció hasta bien entrado el siglo XX, de hecho sólo con la entrada en vigencia de la nueva Constitución en 1992 se dio un reconocimiento de derechos a las minorías étnicas y a la diversidad cultural de la nación. Muchas de los campos teóricos, métodos y enfoques epistemológicos fueron usadas para afianzar la exclusión. Mediante argumentos extraídos de la psicometría, la psicología, la estadística y la medicina; saberes modernos, establecidos para reforzar la clasificación.

La Modernidad en Colombia ha implicado diferentes aspectos, al punto que es necesario hablar de modernidades. Se resalta el papel de la economía del café en la creación de un "hombre nuevo". Concepto nada utópico ni religioso; evoca la formación de ciudadanos que respondan a los requerimientos de un proyecto socioeconómico. Debe interpretarse este tipo de expresiones al revés: "hombre nuevo" significa nuevas formas para resguardar el estatus quo. 
Para que lo "nuevo" se acepte como mejor, se desarrolla una estrategia de naturalizaciones, estas consisten en aceptar lo dado como tal, por la fuerza del tiempo y la tradición, (Bajtin, 1985), (Bourdieu, 2007), son puestas en escena en la cultura y la sociedad en el desarrollo de la Colombia republicana desde finales del siglo XIX y el siglo XX. Sólo a principios del Siglo XXI ha surgido una visión crítica del modelo de desarrollo social.

El tema de la evaluación en educación conlleva estudiar el significado de que es y representa lo moderno y la Modernidad en educación, cómo históricamente se han dado las prácticas de evaluación. Y se hace necesario introducir un concepto que distingue la evaluación de la calificación. Y muestra que calificar ha sido una práctica continua y generalizada porque mermita que el sistema educativo funcione como un artefacto de clasificación y de separación de los más aptos, del común menos capacitado, bajo un modelo exclusivista.

La evaluación tiene como finalidad corregir errores en el sistema educativo y propiciar el desarrollo de una práctica de enseñanzaaprendizaje que permita a los estudiantes su autonomía crítica, su capacidad para aprender, entendiendo que estudiar e investigar, son un coproceso, que es personal e intransferible. Calificar es clasificar y permitir sobre esa clasificación seleccionar los que "ganan el año" de los que lo "pierden".

Se ha dado a lo largo del tiempo un registro de discursos pedagógicos, educativos y científicos, los cuales fueron limpiados de sus perspectivas seculares por una sociedad inspirada en directrices tradicionales, y dentro de ellas, ha habido un rol protagónico de la Iglesia Católica y los partidos hegemónicos en Colombia, el Liberal y el Conservador (Ruiz, 2015).

Se advierten diferencias históricas y antropológicas en la apropiación que hicieron unos y otros de aspectos de la modernidad, pero se remarca que en la defensa de privilegios (estatus socioeconómico, abolengo, educación superior para unos y no para la mayoría, uso de las jerarquías, entre otros) no fueron modernos.

Los profesores Rubén Jaramillo, Gerardo Molina o Jaime Jaramillo Uribe, entre otros, denominaron esta situación modernidad tradicional, modernidad inconclusa o modernidad sin modernización; al respecto se puede consultar el ensayo de Corredor, 1992. 


\section{¿Cómo y desde dónde se ha pensado la evaluación en Colombia?}

Pese a que la evaluación es un tema de consulta, investigación y debate académico, ésta no se ha abordado desde un desarrollo de los estudios sociales de la ciencia y desde el enfoque de la Sociología de la ciencia, ni de los problemas propios de una pedagogía de la ciencia. Son temas que apenas están naciendo y sobre los cuales no se han desarrollado de manera madura grupos de investigación, al respecto puede consultarse la teoría del Actor-Red, de Latour (2001).

Los estudios sobre la formación y la consolidación de la evaluación educativa han sido restrictivos. Lo que ofrecen las disciplinas que se ocupan del tema se resume en trabajos que asocian la formación y la consolidación de la evaluación educativa con la invención, desarrollo y uso de un conjunto de instrumentos o técnicas que permiten diseñar y construir diferentes pruebas. El lenguaje de estos trabajos hace caso omiso de los contextos sociales desde los, y para los cuales, se formó la evaluación educativa. Estos discursos no atienden a criterios históricos, culturales o sociales; reducen el problema de la evaluación educativa al campo técnico, instrumental y de desarrollo de la prueba y los mecanismos de su validación.

Los trabajos sobre evaluación obvian lo concreto, por tal razón desvalorizan las situaciones sociales, políticas, culturales o económicas en las cuales se constituyó la evaluación educativa. Los lenguajes abstractos, esencialistas, sentencian: "la evaluación educativa es producto del desarrollo, el progreso de Occidente, especialmente de la ciencia" (Bajtin, 1985). Por tal razón, un momento de la evaluación educativa, -aquel relacionado con la formalización técnica cuyo producto predilecto son las pruebas-, de acuerdo con estos discursos, se presentan como la totalidad de la misma.

La construcción de estos lenguajes abstractos y técnicos no es casual. Reflejan intereses de grupos dominantes que a través del Estado defienden sus banderas. Lo técnico aparece como lo deseable y necesario que requiere una sociedad; en otras palabras, lo técnico es una cortina que oculta los intereses políticos de grupos dominantes. Presenta lo político como apolítico. Nuevamente el fenómeno se explica por el producto (pruebas) y no por las circunstancias sociales, políticas, culturales o económicas involucradas con su origen. 
En la investigación realizada para escribir éste ensayo se llegó a la convicción que la evaluación educativa es un indicador histórico y una fuente de la cultura y de las políticas públicas en educación de una sociedad en un periodo de tiempo determinado. ¿Cuáles son las condiciones para que exista evaluación educativa? El dictamen es un período: modernidad, aunque discutible si se va a ella para rastrear productos técnicos y no las diferentes circunstancias e intereses relacionados con la evaluación. No obstante, la evaluación como medio de optimización y eficiencia va más allá de la Modernidad y existen antecedentes comprobados, de formas de evaluación que pueden ubicarse en la China de la dinastía Xia (3 mil años a.n.e.) y en la Grecia del siglo V (a.n.e.).

La formación y consolidación de la evaluación educativa tiene relación con dos procesos que corresponden con culturas y períodos históricos. Éstos se sobreponen y entrecruzan, lo cual quiere decir que uno no es superación del anterior. Un proceso que ayuda a comprender la formación y consolidación de la evaluación educativa está asociado con las clasificaciones sociales que disponen para cada individuo un lugar en la sociedad de acuerdo con criterios políticos, culturales, económicos o sociales.

Estas clasificaciones son consideradas procesos naturales, conforme con disposiciones suprasociales que generalmente se atribuyen a una divinidad. Formas de pensamiento natural justifican tales creencias y defienden estas clasificaciones como producto de largas tradiciones, una voluntad divina o consideraciones seudocientíficas que se apoyan en la herencia o el innatismo.

Las clasificaciones sociales perduran gracias a la construcción de mitos que las justifican y que son compartidos por los miembros de la sociedad, entendida como campo de convergencia de los fenómenos culturales y de la comunicación. Son mitos que defienden intereses de sectores dominantes y que están articulados con la conservación del estatus quo. De diferentes formas, las clasificaciones sociales inciden, de una u otra manera, en todos los aspectos de la vida del individuo: en donde vive, en lo que hace, en lo que estudia, en las relaciones afectivas, etc.

El otro proceso articulado con la evaluación educativa es la selección. Ésta se relaciona con los logros científicos y técnicos de la modernidad. Aunque en la selección se acogen premisas de corte natural su campo de acción es especializado: los mundos laboral y educativo. La justificación 
supra-social, propia de la clasificación social, es reemplazada ahora por una científica, especialmente técnica, que utiliza lenguajes apolíticos que concitan el respaldo de la población, neutralizan las críticas y ocultan intereses políticos y económicos de sectores dominantes. No obstante, la presencia del pensamiento natural continúa, ahora combinado con discursos científicos.

Pensamiento natural se entiende aquí como un discurso que justifica situaciones sociales recurriendo a factores suprasociales. No se refiere a la corriente de ideas asociada con la llustración que atacó la escolástica con la defensa del estudio de la naturaleza. En el sentido que aquí se utiliza, el concepto de natural fue acogido por los economistas clásicos como gobierno "divino" del universo que actúa sobre nuestros problemas y que está sobre el poder del Estado, (Smith, 1961). Que permite el desarrollo moral, la independencia de la economía de la moral sólo se hizo entrado el desarrollo de la etapa industrial y especulativa del capitalismo (Smith, 2004).

Pierre Bourdieu define natural en los siguientes términos: "Cuando, como resultado de la casi perfecta coincidencia entre estructuras objetivas y las estructuras internalizadas que resultan de la lógica de la simple reproducción, el orden cosmológico y político no se perciben como arbitrarios, es decir, como una posibilidad entre otras, sino como el orden evidente y natural, que resulta obvio y, por tanto, no se cuestiona" (Bourdieu, 1972).

La propuesta de los planos práctico y de elaboraciones recoge aportes de la teoría de los géneros discursivos de (Bajtin, 1985) y de habitus de (Bourdieu, 2007). De éste mismo autor se pueden consultar: El sentido práctico, Los herederos: los estudiantes y la cultura, La distinción. Crítica social del gusto, ¿Qué significa hablar? Economía de los intercambios lingüísticos.

De esta manera, la evaluación (clasificación social y selección), contiene un plano práctico que incide de una $\mathrm{u}$ otra forma en la vida de las personas. Evaluar como clasificación social o selección, tiene relación con las elecciones que se hacen, las relaciones sociales que se establecen, las costumbres y hábitos que se cultivan; en fin lo que se piensa y hace. Este plano práctico se sustenta en otro conformado por elaboraciones sociales, culturales, políticas o económicas que justifican la posición social de las personas; estas elaboraciones contribuyen a configurar lo que piensan y hacen los sujetos. 
Estos dos planos se complementan y refuerzan. El plano práctico refleja de manera más clara todas las apropiaciones y transformaciones que impulsa la evaluación en las sociedades. En el plano de las elaboraciones se absorben, articulan y reelaboran parte de lo que se produce en el práctico. Para ello se recurre a aspectos culturales (religión, ciencia, costumbres, saberes) que permiten construir proyectos o propuestas de índole política, social, cultural o económica. El plano práctico involucra a todos los sectores sociales; en el de las elaboraciones, sectores dominantes que plasman en ellas sus intereses.

Los dos planos constituyen correas de transmisión que actúan en la historia de las sociedades. En ambos planos se reconocen las estructuras sociales externas de las cuales hace parte la evaluación educativa, tales como el sistema educativo pero también las estructuras sociales internalizadas, incorporadas en los sujetos en forma de esquemas de percepción, pensamiento y acción. La propuesta de los planos práctico y de elaboraciones recoge aportes de la teoría de los géneros discursivos de (Bajtin, 1985) y de habitus de (Bourdieu, 2007).

En coherencia con lo anterior una historia de la evaluación educativa es una historia de las condiciones que la hacen posible. En otras palabras la evaluación educativa requiere de procesos de homogenización social, política, cultural y económica; de apropiación del discurso científico en el sistema educativo; de privilegiar patrones sociales universales, -como el mérito-, antes que patrimoniales -como los heredados-. En lo definitivo, la evaluación educativa requiere de sociedades modernas, con culturas políticas, sociales, económicas que fundamentan méritos antes que privilegios patrimoniales. Es decir, sociedades que favorecen la inclusión, la igualdad; la democracia.

¿Qué sucede en sociedades desiguales en las cuales se instala el discurso y las prácticas de la evaluación educativas? Que la evaluación refuerza y justifica las estructuras sociales, sus clasificaciones y sus desigualdades. Estas situaciones se soslayan por medio de justificaciones ideológicas, -tal el caso del pensamiento natural- o acudiendo a la fuerza de la técnica y la necesidad de su aplicación -para el desarrollo, el progreso, la calidad-en sociedades como la colombiana.

La formación y consolidación de la evaluación educativa en Colombia, está relacionada con proyectos político-económicos de sectores dominantes, situaciones sociales determinadas. El uso de la educación 
durante las repúblicas conservadora y liberal, impulsó el modelo desarrollista de inserción de las políticas púbicas esenciales, como la educativa, en un proyecto continuo de dependencia de las necesidades internacionales y no de lo nacional. Con el incipiente desarrollo de las clases medias nacionales $y$, por otra parte, con la articulación entre clasificación social, evaluación educativa y saberes científicos. La formación y consolidación de la evaluación educativa transcurre en la Colombia de la primera mitad del siglo $\mathrm{XX}$, aunque parte de su arraigo cultura proviene desde la Colonia.

Los usos sociales de la evaluación educativa fortalecen las diferenciaciones sociales, de esta forma la evaluación reproduce en el campo simbólico el sistema de diferencias sociales. Para ello, la evaluación educativa apropia prácticas y discursos tradicionales y científicos "ya constituidos en y por el uso, y objetivamente caracterizados por su posición en una jerarquía de estilos que expresa la jerarquía de los correspondientes grupos. Estos estilos, sistemas de diferencias clasificados y clasificantes, jerarquizados y jerarquizantes, dejan su huella en quienes se los apropian" (Bourdieu, 2007, p. 28). Estos discursos y prácticas son los de sectores de la sociedad que imponen como legítimo, verdadero, moral y útil aquello que beneficia sus intereses. De esta manera, la clasificación social, la evaluación y la selección, son prácticas y discursos acordes con sectores dominantes de la sociedad colombiana.

Aquello que deja huella en quienes lo apropian "tarde o temprano lo escuchado y lo comprendido activamente resurgirá en los discursos posteriores o en la conducta del oyente", lo cual implica que incide en los miembros de la sociedad (plano práctico) sin que levante mayores críticas. A su vez, lo apropiado conforma una comunidad epistemológica en cuya defensa están de acuerdo unos y otros, sin importar el color político de sus ideologías o partidos. Por tal razón lo apropiado se convierte en dispositivo que permite la conservación de privilegios tradicionales (Bajtin, 1985).

En su crítica a la modernidad, Nietzsche (1990) advierte que el conocimiento es una invención y la verdad una metáfora: "en suma de relaciones humanas que fueron poética y retóricamente intensificadas, transpuestas y adornadas y que después de un largo uso parecen a un pueblo fijas, canónicas y vinculantes". En esta dirección lo importante del conocimiento no es tanto lo que en él hay de verdad sino su antigüedad, el tiempo de incorporación de él en las personas, la apropiación que de él hacen los individuos. 
Una vez incorporados por las sociedades pasan a ser parte de una lucha por el poder, en la cual el dominio de las elites del Estado favorece el dispositivo de saberes acordes con proyectos político-económicos. Esta estrategia de control y disciplinamiento de la población dócil y productiva implica una normalización del conocimiento, entendida como que sectores dominantes de la sociedad, representados en Mariano Ospina Rodríguez y Gabriel Betancur, indican lo que puede o no enseñarse y conocerse. Sobre disciplinamiento de la ciencia véase: Foucault, 2000; Feyerabend, 1990. Sobre verdad y conocimiento, véase: Nietzsche, 1990; 2002.

Lo característica central de estos proyectos políticos-económicos, -como el de Mariano Ospina Rodríguez, Rafael Núñez, Antonio José Uribe, Gabriel Betancur- fue su conservadurismo. Fueron proyectos que reconocían la importancia de la educación dentro de la modernidad pero rompían el vínculo entre cultura y sociedad, lo cual les permitió emprender críticas contra aquellos valores de la modernidad que atentaban contra la tradición (verbigracia: modas, laicismo, libertad de pensamiento, entre otros) y aceptar, saberes técnicos o instrumentales que implicaban que los individuos adecuen sus acciones con las necesidades de la razón instrumental que caracteriza la producción industrial o vinculada en forma dependiente a la gran industria, como era Colombia, un país proveedor de materias primas.

En este sentido no es casualidad que criticaran aspectos de la educación que consideraban tradicionales, -el castigo físico de los escolares; el abuso de la memoria; o la repetición o la mecanización como estrategias para aprender a leer y escribir- porque ellos no son coherentes con adecuación entre población y producción. No obstante, a la par, enfilan armas contra aquellas mujeres que montan a caballo a horcajadas.

\section{Evaluación educativa y modernidad}

Modernidad implica la necesidad de formación de ciudadanos. Supone su semántica un proceso caracterizado por una lenta construcción de un ser "humano nuevo" o por lo menos diferenciado de aquel supuesto, que fue formado en sociedades tradicionales como el Antiguo Régimen en Europa y la época Colonial en Hispanoamérica, y durante la transición del sistema colonial al republicano en el siglo XIX. Un ser "humano nuevo" se 
teje en ambientes que trascienden las relaciones serviles que anudaron la economía de buena parte del siglo XIX. Es "nuevo" en oposición al tradicional, es decir, son hombres y mujeres que a la fuerza acogen valores relacionados con el uso adecuado del tiempo, la defensa de la individualidad, la importancia del mérito y la educación, por citar algunos de los que supone la racionalidad moderna.

En Costumbres en Común, Edward Palmer Thompson (1924-1993), llama a este proceso apropiación de una "naturaleza humana" acorde con el progreso o desarrollo económico. En Colombia, Luís Eduardo Nieto Arteta (1913-1956) consideró que a finales del siglo XIX y principios del XX se produjo una transformación del ser del hombre colombiano. Al final, según Nieto Arteta, surgió un colombiano acorde con la modernidad, concepto claramente descrito en la obra de (Thompson, 1995). En concordancia con el profesor Jaime Jaramillo Uribe, la modernidad impulsó el reemplazo de una concepción nobiliaria de la vida por una burguesa, sustituir el caballero cristiano por el hombre económico, apropiar la ciencia moderna e introducir las ideas racionalistas y positivistas, (Uribe, 1996).

¿Qué propició la formación de una "naturaleza humana" proclive con la modernidad o un "hombre nuevo", de acuerdo con la descripción de Nieto Arteta? En el caso colombiano, el café fue el detonante principal. Este producto acostumbró a los colombianos a los salarios y a la regulación del tiempo; también, favoreció la discusión e implementación de proyectos educativos que propendían por lo práctico sobre lo humano. Esta idea se configuró desde mediados del siglo XIX con Mariano Ospina Rodríguez y la acogieron gobernantes de la República Conservadora. Proyecto articulado con el café y una perspectiva de economía, centrada en la exportación del grano, las haciendas y un tipo de dominación tradicional. Como en la mayoría de los países indoamericanos, los procesos de modernización fueron liderados por sectores conservadores de las elites políticas y económicas. Véase el caso argentino en, (Blanco, 2008).

La propuesta conservadora tomó fuerza por diferentes razones. En el plano internacional, el mundo político de finales del siglo XIX y principios del XX giraba a la derecha. En el plano nacional, aunque los liberales pusieron en práctica parte de su ideario, los alcances de los gobiernos que lideraron entre 1849 y 1880 fueron cooptados por los gobiernos conservadores, aunque el discurso de éstos fue crítico y destructivo con la obra de sus predecesores. 
A diferencia de la modernidad conservadora, la liberal se distinguió por impulsar un sistema republicano con la separación de poderes públicos y el voto popular -restrictivo, versión draconiana; universal, versión de los Gólgotas- para elegir a funcionarios públicos. A más de lo anterior, impulsaron elecciones populares para elegir a los miembros del Congreso, el fin del fuero eclesial, un país federal y por tanto, un ejecutivo sin tanto poder.

El ideario educativo tenía similares inclinaciones: abolición de los títulos para fomentar o avalar la formación autodidacta, fue una de ellas. Los exámenes servirían para homologar los conocimientos de quienes aspiraran a optar por una $u$ otra profesión, así no hubieran pasado por claustros universitarios. Además, en lo social, se distinguieron por fomentar la libertad absoluta de imprenta, y de palabra, libertad religiosa y de enseñanza, supresión de la pena de muerte, disminución de penas por delitos, juicios por jurados, expulsión de los jesuitas, entre otros. Saltaba a la vista las diferencias entre una modernidad impulsada por conservadores y otra, por liberales. La evaluación educativa externa fue canalizada por una modernidad conservadora (Molina, 1970).

"Nuevos valores" reclaman "hombres nuevos", con la suficiente fuerza -económica, política y cultural- para expandir los nuevos derroteros. Clases medias que se comprometan con patrones universales antes que locales, al decir de Safford (1977). En Colombia, las clases medias de inicios del siglo XX no tuvieron la fortaleza suficiente para llevar a buen término la tarea enunciada. Además, inclinaron sus intereses con los de las elites.

La debilidad de las clases medias colombianas de la primera mitad del siglo XX se observa en la escasa injerencia que éstas tuvieron en educación. En la coyuntura de la diversidad de bachilleratos -primera mitad del siglo XX-, de la cual dependía el ingreso a la universidad, las clases medias aceptaron que el considerado bachillerato académico fuera el único que garantizaba ingreso directo a la educación superior. Como consecuencia, los egresados de otras modalidades de educación media debían someterse a variopintos procesos de selección que pasaron por las manos de las propias instituciones educativas, el Ministerio de Educación Nacional y algunas instituciones de educación superior.

Desde la perspectiva del maestro Gerardo Molina la debilidad de las clases medias se explica por la discrepancia entre la intención del Partido 
Liberal de insertar la economía del país en el mercado internacional y la realidad, que encausó dicha inserción a través de la producción de materias primas. Lo anterior significa un escaso desarrollo de las fuerzas productivas del país o una inserción en la periferia del sistema mundo capitalista. Ello dificultó romper las formas tradicionales de producción, así como las corporaciones económicas propias de la Colonia. En pocas palabras, la economía de la primera mitad del siglo XX, sustentada en la producción de materias primas, se mantuvo en condiciones no del todo capitalistas. En palabras del maestro Molina:

"al proclamar los liberales la ruptura total con la Colonia al tiempo le abrían paso a una forma más peligrosa de colonialismo, la que se crea entre los países productores de alimentos y materias primas y las naciones industriales" (Molina, 1979).

Ello dio como resultado clases medias débiles, con escaso poder político, económico y cultural que les permitiera apoyar reformas sustanciales y proclives a diferentes intereses y políticas contradictorias a las clases dirigentes del país.

En el Cono Sur, en cuyos países hubo mayor variedad de bachilleratos, clases medias con poder político, económico y cultural defendieron la universalidad de ingreso a la educación superior. De tal forma, la mediación de exámenes de selección no fue una opción que se diera en dichas latitudes y tiempos.

Sumemos a lo anterior, la debilidad de las clases medias colombianas en el terreno educativo, la precariedad de la educación. El modelo de educación excluyente tenía parangón en una estructura que excluía: baja cobertura, especialmente en educación superior; escaso presupuesto que convivía con un modelo de descentralización administrativa que evitaba responsabilidades y clientelismo, son síntomas de exclusión que advirtieron misiones extranjeras. Éstas recomendaron a los políticos nacionales colocar más atención a la educación. Sugerencia que logró atención entrado el Frente Nacional.

El examen de selección representó solución al problema de ingreso a la educación superior, en un país con un enorme déficit de cupos en este nivel de educación. También, la selección indica la adopción en educación de directrices modernas que implicaron apropiación del 
modelo experimental el cual llegó a través de la psicología, la medicina y la pedagogía. La selección obra sobre un "hombre nuevo", sujeto que debe aprender determinadas habilidades, actitudes y conocimientos que son susceptibles de medición a través de pruebas estandarizadas.

El proyecto de adecuar la educación del siglo XIX con los cambios del siglo $X X$, empezó a mediados del primer siglo señalado. Fue impulsado por gobernantes-empresarios que defendieron políticas económicas centradas en la exportación de materias primas, de las cuales el café fue el caso con mejores resultados. Una primera fase de esta adecuación culminó a mediados del siglo XX, momento en el cual los gobiernos acogieron recomendaciones internacionales para ajustar el sistema educativo en lo administrativo, pedagógico y político. Uno de los logros de estos ajustes fueron planes de estudio nacionales, requerimiento indispensable para diseñar, construir, aplicar y clasificar estudiantes mediante pruebas estandarizadas. Antes del Decreto 045 de 1962, hubo intentos por tener planes de estudios nacionales, todos los cuales fracasaron por diferentes motivos. Sobre el Decreto 045 de 1962 se sustentaron las pruebas que conformaron los primeros exámenes de Estado. Este decreto estuvo vigente hasta 1974.

La emergencia de exámenes de selección para ingreso a la educación superior hace parte del proceso de modernización de la economía. Esto es, la inserción de ésta en los mercados mundiales a través de la exportación de materias primas. Ello implicó cambios en las formas de producción, costumbres y valores de los colombianos; amén del impacto en la infraestructura económica (construcción de ferrocarriles, carreteras, puertos, aeropuertos, entre otros) y en el crecimiento de las ciudades. En educación la modernización de la economía impulsó proyectos que acogieron los derroteros de las ciencias. En especial, la apropiación y aplicación de los principios del positivismo en pedagogía.

Articular la educación con la modernización de la economía, además de apropiar los principios de la ciencia, acarreó modificaciones que afectaron la estructura del sistema educativo y las prácticas pedagógicas. Centralizar la administración, implementar planes de estudios nacionales, formar docentes en las nuevas corrientes pedagógicas, modificar la normatividad y responder a la demanda de cobertura en los diferentes ciclos, fueron algunas de las transformaciones estructurales. En el campo de las prácticas, significó formar un nuevo sujeto educativo, acorde con las exigencias del mundo moderno, que aprendiera 
habilidades, destrezas, actitudes y conocimientos útiles. Este sujeto es objeto de medición a través de pruebas estandarizadas. Conviene advertir que la transformación de la "naturaleza humana" afectó los diferentes campos de la actividad humana, no solamente el educativo.

En el caso colombiano la ausencia de clases medias con poder económico, político y cultural durante la primera mitad del siglo XX dejó los proyectos educativos en manos de elites que adoptaron los nuevos esquemas de educación en odres viejos. En otras palabras, la selección educativa tiene sentido en países donde las condiciones sociales, políticas y económicas garanticen el mérito. En un país con déficit educativo, los exámenes de selección favorecieron a determinados sectores, antes que a la mayoría.

En este aspecto puede apreciarse una diferencia entre una modernidad conservadora y liberal. La segunda, atendiendo a las características expuestas por el maestro Gerardo Molina, hubiera preferido sanar el déficit educativo antes que implementar procesos de selección.

Pero el peso de la tradición dominante en la educación y la cultura perpetúa formas de explotación social y dominación político-cultural. Tal proceso lo realiza acudiendo a la clasificación-evaluación, que refuerza las estructuras clasistas de diferenciación desigual, a contravía de la diferenciación entre iguales. Son los asuntos de la diferencia como valor positivo y la desigualdad como valor negativo.

La articulación entre clasificación social, evaluación educativa, evolucionismo y positivismo, nos lleva a rastrear los orígenes de la evaluación educativa. A diferencia de otros trabajos que buscan en las normas o desarrollo de determinadas disciplinas (como la psicología) los orígenes de la evaluación, en éste acudo a la cultura colombiana.

La clasificación social ha sido una actitud constante más en unas sociedades que en otras. En el caso colombiano se dio un modelo de dos etapas de clasificación social: la natural y la científica; una y otra se respaldan. La primera justificó formas de clasificación social durante la Colonia y el siglo XIX. Natural implica que los prejuicios que afirman que los blancos eran superiores, en tanto que los mestizos, indígenas y negros eran inferiores estaban sobre cualquier discusión. Principio natural implica leyes de orden divino que están sobre los seres humanos y los Estados. 
Durante la Colonia, la "superioridad" del blanco se reflejó en la organización del territorio. El damero transmite una organización del espacio urbano que a la vez clasifica a la población que lo habita. La apropiación de este esquema por parte de la población fue lenta pero segura, de tal forma que no admite cuestionamientos. ¿Qué más natural que el paisaje?

El análisis del territorio ejemplifica el propósito de la clasificación social: ordenar para controlar. Durante la Colonia la clasificación social abarcó todos los ámbitos de la vida cotidiana: el religioso, el cultural, el económico, el administrativo, el político; entre ellos, el escolar es un caso.

Una vez en el país empezó la apropiación de la modernidad, la clasificación social no desapareció. Se afianzó y consolidó con el apoyo de discursos "científicos". El método experimental se presentó con diferentes ropajes: evolucionismo, positivismo, objetividad, fueron los principales. De todos ellos, la tradición de la clasificación social coadyuvó a fortalecer o a adaptar aquellos que apoyaban la superioridad de unas "razas" sobre otras, sustentada en la herencia y en los genes.

La discusión sobre la decadencia de la raza, muestra la articulación entre el discurso de clasificación social con discursos científicos construidos al amparo del evolucionismo. Tal el caso de la craneometría y la eugenesia. Esta articulación permitió afianzar la clasificación social. Como consecuencia de ello, el sistema educativo promovió proyectos para mejorar la raza que incluyó adquirir hábitos de higiene, salud y nutrición propios de la modernidad. En el campo pedagógico implicó considerar a la mayoría de la población en estado de inferioridad. Para sacarla de ella, políticos, pensadores y empresarios se dieron a la tarea de enseñar con el ejemplo.

Lo que acontecía en estas latitudes en el plano político, económico y cultural correspondió con un giro a la derecha en el mundo. Lo anterior se explica en parte porque las revoluciones de mediados del siglo XIX, la Revolución industrial y la reacción frente a las masas, hicieron que el pensamiento científico y político de finales del siglo XIX y comienzos del $X X$, rechazara las inclinaciones sociales que se dieron en la Europa del sigloXIX.

La apropiación del evolucionismo y del positivismo hizo cada vez más difícil sostener la clasificación social en todos los campos, con la cual 
ésta se vio confinada a la educación. En esta trinchera, la clasificación se articuló con la medición y su pretensión de valorar con objetividad rasgos de la personalidad humana. El prestigio del número, del cual hace uso y abuso la psicometría, dejó poco margen al cuestionamiento.

Durante la primera mitad del siglo $\mathrm{XX}$, diferentes instituciones realizaron pruebas para seleccionar estudiantes. No obstante, en la década de 1960 confluyen la reorganización de la educación, la financiación de algunos proyectos en el marco de la Alianza para el Progreso y la formación en medición, de un cuerpo de profesores de las universidades Nacional y Antioquia. Esta coyuntura contribuyó a la formalización de una entidad técnica que garantizara "imparcialidad" y "objetividad" en la selección de estudiantes para ingreso a la educación superior.

La apropiación o asimilación de la propuesta de medición estadounidense fue parcial en dos sentidos. La taxonomía de Benjamín Bloom se adoptó sin la sustancia. En su versión original, Bloom buscaba evaluar para rastrear hasta qué punto se cumplían los objetivos de formación y los planes de estudio. Sólo después de esta labor, podía evaluarse (en términos de medición) a los estudiantes. En Colombia, se adoptó la medición en términos de selección de estudiantes para ingreso a la educación superior.

Por otra parte, los esquemas de medición apropiados eran objeto de fuertes cuestionamientos en Europa y Norteamérica. A finales de los años 1960, la psicometría cursaba la segunda generación, ésta se caracteriza por promover técnicas cualitativas y cuantitativas de evaluación. El propósito era superar las pruebas cognitivas como indicador de calidad. Pese a ello, en el país se adoptó la primera generación, que enfatiza medir la calidad de la educación vía pruebas estandarizadas.

La apropiación de la clasificación social en la cultura colombiana fue lenta y segura desde la Colonia hasta mediados del sigloXX. La impronta de la clasificación se observa en que los miembros de una u otra clase social, corriente política o credo religioso, la aceptaron y defendieron. En algunas situaciones, especialmente durante la primera mitad del siglo $\mathrm{XX}$, sectores sociales protestaron para reivindicar derechos por tierras, laborales o sociales; sin embargo, la impronta de la clasificación social no se tocó, pasó diferentes pruebas. 
Esta impronta hace parte de una sociedad en la cual se exaltan valores tradicionales, se inhibe la dinámica social, económica y política, y se facilita la exclusión y la desavenencia. Es una sociedad que fomenta el fatalismo y el determinismo justificado en fuerzas religiosas.

Todo ello tiene antecedentes más hondos. La defensa del honor sin provecho que impulsa el rechazo de las artes y oficios considerados viles, fue un freno contra cualquier proceso económico que trajeron los españoles desde la península de la Contrarreforma. En la España de Carlos V y Felipe II, el honor, el dogma religioso y la pureza de sangre, fungen como armas que inhiben el desarrollo económico a la vez que excluyen a los sectores dinámicos de la sociedad, es decir, quienes comercian y realizan trabajos manuales. Ellos son considerados inferiores.

Las voces discordantes contra estas prácticas fueron pocas pero existieron. Se cuentan entre ellas Luís de Ortiz y Gaspar Gutiérrez de los Ríos, quienes pregonan la defensa de los que trabajan y la condena de los ociosos. El mismo Felipe II se opuso a los Estatutos sobre limpieza de sangre, pero la presión de sectores poderosos lo llevó a aceptarlos (Peyrefitte, 1996).

Producto de la defensa del honor, le dogma religioso y la pureza de sangre las exclusiones son colectivas: indios, mestizos, negros son aislados y tratados como menores de edad. En lugar de reconocer el mérito y los logros de los individuos, se convalida el origen como indicador natural de la posición social. Quienes tienen mancha de sangre y traicionan el dogma religioso no pueden acceder a cargos ni dignidades. Estos hábitos mentales, interiorizados por la población, perduran hasta finales del siglo XIX, con lo cual quitan vitalidad a la sociedad.

Entrado el siglo $X X$, las innovaciones pedagógicas propuestas al tenor de las luces de las modernas corrientes educativas, importan propuestas de selección educativa a una sociedad que aún defendía el honor, el dogma y la pureza de sangre. La mentalidad dominante de 300 años atrás, sobrepone a la selección educativa los rasgos de la clasificación social. Con ello los instrumentos de medición constituyen formas de exclusión social similares con el orden educativo que privilegió entre los diferentes bachilleratos aquellos que cursaban los hijos de las elites. 


\section{¿Qué significa modernidad en evaluación educativa?}

Los proyectos de educación moderna pretendían oponerse a la educación tradicional. Quienes impulsaron estos proyectos en la educación colombiana -Mariano Ospina Rodríguez, Antonio José Uribe, Miguel Jiménez López, Agustín Nieto Caballero- debieron acoger las ciencias, los nuevos rumbos de la pedagogía (escuela activa, escolanovismo) y dejar atrás el abuso de la memoria (entendida como repetir), los castigos y relaciones entre docente y estudiantes que privilegiaban la voz del primero sobre el segundo. Un completo análisis sobre lo que implicó modernidad y educación en Colombia se puede encontrar en Sáenz Obregón, Saldarriaga, \& Ospina (2010).

En general las sociedades modernas demandan superar las relaciones sociales, culturales, políticas y económicas tradicionales. La modernidad pregona valores como la valoración del tiempo, el afán de lucro, la búsqueda individual del éxito, la iniciativa individual, la movilidad territorial y social, entre muchos otros. El paso de una sociedad tradicional a una moderna implica innumerables tensiones; una de la más importante conlleva que los sujetos modernos (ciudadanos) apropian una nueva naturaleza. Sobre los cambios que implica la modernidad véase, Thompson, 1995; Peyrefitte, 1996. Para Colombia véase, Nieto Arteta \& Safford, 1977.

La inserción de la educación en proyectos internacionales, la estandarización, la centralización y la adopción de saberes científicos y técnicos son características que hacen de la evaluación educativa un proyecto moderno. No olvidemos la pauta económica y tradicional de la modernidad colombiana, en la cual está inserto el proyecto educativo, razón por la cual las características enunciadas se acoplaron en una estructura educativa tradicional que a su vez se articulaba con estructuras sociales, políticas, económicas y culturales de igual sentido.

La educación fue antes del uso y abuso del concepto de globalización una manera de inserción asimétrica de Colombia y sus elites en lo global, privilegiando los proyectos internacionales a cualquier proyecto interno de nación. Se presentó a través de diferentes circunstancias, siempre asociadas con las experiencias de vida de políticos e intelectuales de sectores dominantes. Así, por ejemplo, gracias a sus prolongadas 
estadías en Europa y Estados Unidos, Mariano Ospina Rodríguez asimiló las nuevas corrientes educativas que estaban en boga en sociedades consideradas desarrolladas. Esta experiencia le permitió contrastar la educación de estas sociedades con la nacional y formular propuestas educativas que articulaban la educación con un proyecto económico de carácter internacional.

Otra forma de insertar la educación nacional en proyectos internacionales fue a través de la formación de intelectuales nacionales en Europa y Estados Unidos. Tal el caso de Miguel Jiménez López y Agustín Nieto Caballero quienes realizaron estudios de pregrado y postgrado en centros especializados en pedagogía. Una vez en Colombia, impulsaron proyectos educativos, El Gimnasio Moderno y la experiencia educativa adelantada por el departamento de Boyacá, que marcaron hitos en la educación colombiana. No es de extrañar que en Europa y Estados Unidos existieran instituciones o grupos de personas interesadas en divulgar sus ideas pedagógicas en América Latina. Al respecto, vale la pena examinar la obra reciente de Herrera \& Low, 1994.

La estrategia más clara para insertar la educación en proyectos internacionales fueron las misiones extranjeras que diferentes gobiernos durante finales del siglo XIX y la primera mitad del siglo XX contrataron con la expresa misión de modernizar el sistema educativo nacional. Las misiones permitieron articular la educación colombiana con proyectos internacionales, baste mencionar los casos de las misiones de mediados del siglo XX (Unesco, Harvard), una perspectiva amplia del tema puede ser consultada en Ruiz Quiroga, 2012.

Estandarizar implica homogenizar procedimientos, contenidos y habilidades. La evaluación educativa requiere de procedimientos comunes (por ejemplo: igual o similar número de horas a las cuales asisten estudiantes por año lectivo; organización de la vida académica -número de horas por semana, espacios de descanso; metodologías de enseñanza, etc.-); también, que las instituciones educativas tengan un currículo común acorde con demandas internacionales y que la escuela forme y desarrolle habilidades como el recuerdo, el análisis, la comprensión.

Centralización administrativa es otra característica que hace de la evaluación educativa un proyecto moderno. Hay centralización cuando se promulga un currículo nacional, cuando se dan pautas comunes para 
organizar la vida académica, cuando el Estado se hace responsable de la educación, cuando se adopta una postura pedagógica común. La propia evaluación es un conjunto de prácticas estandarizadas desde la concepción de las pruebas, pasando por su aplicación hasta la entrega de resultados. Por último, la evaluación educativa requiere de saberes científicos y técnicos modernos: psicología, administración, estadística, saberes disciplinares (matemática, lenguaje, ciencias naturales y sociales) que implican una concepción de sujeto educativo diferente a la del alumno del siglo XIX.

La evaluación educativa se desarrolló durante la primera mitad del siglo XX y corrió a la par del proceso económico de industrialización del país, impulsado por los gobiernos de Rafael Reyes, las repúblicas conservadora y liberal, el gobierno de Rojas Pinilla y los gobiernos del Frente Nacional. El énfasis económico y tradicional de la modernidad nacional afectó el proyecto de educación moderno. Aunque hubo políticas que impulsaron una educación moderna, ella no afectó de la misma forma a todas las instituciones educativas. Incluso, en algunas regiones antes que apoyo se dio oposición.

De esta manera el término modernización no es evidente por sí mismo ni indica un modelo económico o educativo al cual se ajustaron proyectos de una u otra índole. La modernidad que pensaron y vivieron los sectores dominantes en el período del cual se ocupa esta investigación fue más concreta que abstracta. En mucho consistió en adaptar discursos, técnicas y saberes a la realidad nacional. Para ello recurrieron a la experimentación, entendida como ensayar lo que en otros contextos sociales dio resultado y dentro de ese ensayo-error hicieron los ajustes necesarios.

La evaluación educativa está relacionada con apropiación de técnicas y saberes modernos que afectan de diferente manera espacios y tiempos de las instituciones educativas. En otras palabras, es una forma de racionalización del trabajo educativo. Pero de ello no se siguen modificaciones en las mentalidades, valores, habilidades o cultura de los sujetos educativos. Pese a la trilogía modernidad, modernización y modernismo, la recurrencia a lo moderno durante finales del siglo XIX y primera mitad del siglo XX lleva a reconocer que aquellas acciones modernas estuvieron forzadas por la defensa de tradiciones naturales y por la defensa de intereses de sectores dominantes (Pecaut, 1990). 


\section{Una reflexión final}

¿Por qué tendría que ser la calidad lo más importante en la educación? ¿Qué es calidad en la educación? Todo el mundo da por hecho que la calidad es el tema más importante de todos los que se relacionan directa o indirectamente con el sistema educativo. Es por eso que la evaluación educativa se volvió un tema crucial porque se presume que está intimamente ligada a medir logros y calidad (Ferreira, 2012).

La sociedad industrial avanzada, en la era de la información y el conocimiento, ha hecho del "saber útil en contexto" el medio más importante del valor agregado de productos y servicios, de su estrategia de seguridad y defensa, del control policivo que se hace desde múltiples y sutiles plataformas, en ella se afinca la competitividad estructural y permite diferenciar categóricamente los países desarrollados de los que no lo son.

Desde muchos frentes, uno la psicología evolutiva, la neo-sociología a partir de las neurociencias, tratan que la educación se ha quedado rezagada, con modelos, practicas, principios y valores que fueron creados en la alborada de la modernidad industrial bajo la premisa de una instrucción pública concebida para capacitar mano de obra, técnicos de enlace en las cadenas productivas y la burocracia administrativa de los sectores económicos y del Estado.

Mientras que la sociedad humana se fue transformando, la educación no lo hizo. Corresponde a la pedagogía trabajar siempre en el presente con la construcción de un proyecto humano y social. Hoy la educación debería desarrollar facultades para que las personas vivan felices, a plenitud de sus posibilidades, sin la aprehensión del amedrentamiento de cumplir con expectativas basadas en el lucro, la propiedad, el derroche y la compulsión por el consumo.

La calidad como categoría de evaluación y la evaluación como medio para medir la calidad necesitan salir del enfoque instrumental. Se requiere más calidad en la educación en términos de inclusión y de vencer las barreras de acceso a la educación de más alto nivel. A ella deberían llegar de manera democrática todos los miembros de la sociedad y quienes han sufrido el marginamiento, el desplazamiento, la falta de oportunidades, ellos deberían ser aquellos que recibieran prioritariamente la mejor educación (Orozco, 2012). 
Pero hay preguntas fundamentales pensando en la evaluación, sus fines y vencer su uso para la clasificación social: ¿Cuál es la mejor educación? ¿Quién tiene la autoridad y los criterios para definirla y mostrar cómo aplicarla? Se trata de temas y problemas que abren un campo, no nuevo, pero a la luz de los problemas humanos y naturales de hoy, constituyen un reto para la creatividad, la imaginación, la innovación en pedagogía.

\section{Referencias bibliográficas}

Acevedo Zapata, S. (2015). La formación de profesionales desde la reflexión en la acción con elementos fundamentales de la pedagogía crítica. Revista De Investigaciones UNAD, 14(1), 151 - 169. doi:http://dx.doi.org/10.22490/25391887.1350

Bajtin, M. M. (1985). Estética de la creación verbal. En M. M. BAJTIN, Estética de la creación verbal (pp. 256-57). México-Bogotá: Siglo XXI.

Blanco, J. E. (2008). Modernidad conservadora y cultura política. La Acción Católica Argentina (1931-1941). En J. E. Blanco, Modernidad conservadora y cultura política. La Acción Católica Argentina (1931-1941). Córdoba: Universidad de Còrdoba. Facultad de Filosofía y Humanidades.

Bourdieu, P. (1972). Outline of A Theory of Practique. En P. Bourdieu, Outline of A Theory of Practique.Cambridge: Cambridge University Press.

Bourdieu, P. (2001).¿Qué significa hablar? Economía de los intercambios lingüísticos. Madrid: Akal.

Bourdieu. P. (1988). La distinción. Crítica social del gusto. Madrid: Taurus.

Bourdieu. P. (2009). Los herederos: los estudiantes y la cultura. 2 ed. Buenos Aires: Siglo XXI.

Bourdieu, P. (2007). El sentido práctico. Madrid: Siglo XXI.

Corredor, C. (1992). Los límites de la Modernización. Bogotá D.C.: Universidad Nacional de Colombia Facultad de Ciencias Económicas.

Ferreira, H. (2012). Significados y efectos en torno a la evaluación de los aprendizajes escolares. Revista -RIIEP-/ISSN: 1657-107X / Vol. 5 - No. 2 / Bogotá, D.C. - julio diciembre 2012 / pp. 85 - 92

Feyerabend, P. (1990). Diálogos sobre el método. Madrid: Cátedra.

Foucault, M. (2000). Defender la sociedad. México: FCE . 
Herrera, M. C., \& Low, C. Los intelectuales y el despertar cultural del siglo. El caso de la escuela Normal Superior. Una historia reciente y olvidada. Bogotá: Universidad Pedagógica Nacional.

Jiménez Mendoza, W., Luciano Alipio, R., \& Soto Carrión, C. (2014). Influencia de las fuentes de financiamiento externo en el crecimiento y desarrollo de las empresas agroindustriales del distrito de Abancay Apurímac Perú (periodo 2012- 2013). Revista De Investigaciones UNAD, 13(1), 261-273. doi:http://dx.doi.org/10.22490/25391887.1141

Latour, B. (2001). La esperanza de Pandora, ensayos sobre la realidad de los estudios de la ciencia. Barcelona: Gedisa.

Lurán Rivero, A., Buenahora Tobar, M., \& Vargas Granados, C. (2015). Perspectiva del aprendizaje tradicional y del aprendizaje con comunicación bidireccional en actividades educativas. Revista De Investigaciones UNAD, 14(1), 253-262. doi:http://dx.doi. org/10.22490/25391887.1468

Marín, J. D. (2012). Línea de investigación: currículo y evaluación educativa. Revista RIIEP / ISSN: 1657-107X / Vol. 5 - No. 2 / Bogotá, D.C. julio - diciembre 2012 / pp. 55 - 71

Mitzman, A. (1969). La jaula de hierro: una interpretación histórica de Max Weber. Madrid: Alianza Ed.

Molina, G. (1970). Las ideas liberales en Colombia: 1849-1914. Bogotá: Universidad Nacional de Colombia.

Molina, G. (1979). Las ideas sobre sistema mundo en Wallerstein, I. El moderno sistema mundial. t. 1. México: Aiglo XXI .

Nieto Arteta, L. E., \& Safford, F. (1977). Aspectos del siglo XX en Colombia. Medellín: Hombre Nuevo.

Nietzsche, F. (1990). Sobre la verdad y la mentira en sentido extramoral. Madrid: Tecnos.

Nietzsche, F. (2002). La gaya ciencia. Madrid: Edaf.

Orozco, T. (2012). Los ECAES y la cultura de la evaluación en la educación superior. Revista -RIIEP- / ISSN: 1657-107X / Vol. 5 - No. 2 / Bogotá, D.C. - julio - diciembre 2012 / pp. $85-92$

Pecaut, D. ( agosto-septiembre de 1990). Modernidad, modernización y cultura. Gaceta. № 8.

Peyrefitte, A. (1996). La sociedad de la confianza. Ensayo sobre los orígenes y la naturaleza del desarrollo. En A. Peyrefitte, La sociedad de la confianza. Ensayo sobre los orígenes y la naturaleza del desarrollo (pp. 150-153). Barcelona: Andrés Bello. 
Régio, L., Egry, E., \& Apostólico, M. (2015). Consideraciones acerca de la importancia del estudio de saberes necesarios para el afrontamiento de la violencia infantil en la atención primaria de salud.. Revista De Investigaciones UNAD, 14(2), 137-149. doi:http://dx.doi.org/10.22490/25391887.1463

Rojas Mesa, J., \& Leal Urueña, L. (2014). Entre flujos y fronteras: la educación superior mediada tecnológicamente vista a través de una perspectiva etnográfica. Revista De Investigaciones UNAD, 13(2), 9-27. doi:http://dx.doi.org/10.22490/25391887.1143

Ruiz, D (2015). Aportes de la educación a la evangelización católica de la cultura en Colombia. RIIEP, Vol. 8, N. 2, julio-diciembre de 2015, pp. 239-262.

Ruiz Quiroga, M. (2012). El impacto de las misiones en la educación nacional. El maestro: disputa por los sentidos orientadores de su práctica en la escuela. El caso de las misiones de asistencia técnica en Colombia (1955-1970). Bogotá: Facultad de Educación.

Sabogal Padilla, A. (2014). Retos de la pedagogía en el siglo XXI. Revista De Investigaciones UNAD, 13(2), 143-148. doi:http://dx.doi.org/10.22490/25391887.1153

Sáenz Obregón, J., Saldarriaga, O., \& Ospina, A. (2010). Mirar la infancia. Pedagogía, moral y modernidad en Colombia, 1903-1946. En J. Sáenz Obregón, \& O. y. Saldarriaga, Mirar la infancia. Pedagogía, moral y modernidad en Colombia, 1903-1946. BogotáMedellín: Colciencias-Universidad de Antioquia-UniAndes.

Safford, F. (1977). Aspectos del siglo XX en Colombia. En F. Safford, Aspectos del siglo $X X$ en Colombia. Medellín: Ediciones Hombre Nuevo.

Smith, A. (1961). Indagación acerca de la naturaleza y las causas de la riqueza de las naciones. En A. Smith, Indagación acerca de la naturaleza y las causas de la riqueza de las naciones (pp. 503-504). Madrid: Aguilar.

Smith, A. (2004). Teoría de los sentimientos morales. México: FCE.

Tarde, G. (2011). Las leyes de la imitación y la sociología. Madrid: Centro de Investigaciones Sociales y Agencia Estatal Boletín del Estado.

Thompson, E. P. (1995). Tiempo, disciplina de trabajo y capitalismo industrial. En E. P. Thompson, Costumbres en común. Barcelona: Crítica.

Uribe, J. J. (1996). El pensamiento colombiano en el siglo XIX. Bogotá: Planeta, Colombiana Editorial S.A.

\section{Normatividad en contexto histórico}

Decreto 045 de 1962 


\section{Normatividad vigente de comparación}

Artículo 67 Constitución Política

Ley 30 de 1992- Servicio Público de Educación Superior.

Decreto 1403 de 1993- Reglamentación de Ley 30 de 1992.

Ley 115 de 1994- Ley General de Educación.

Ley 489 de diciembre 29 de 1998. Por la cual se dictan normas sobre la organización y funcionamiento de las entidades del orden nacional.

Decreto 2230 de 2003- Modificación Estructura Ministerio de Educación Nacional.

Decreto 644 de 2001- Reglamentación sobre puntajes altos en Exámenes de Estado

Acuerdo No. 01 de junio 23 de 2005. Consejo Nacional de Educación Superior, CESU, por el cual se expide el reglamento interno de funcionamiento.

Acuerdo No. 02 de junio 23 de 2005. Consejo Nacional de Educación Superior, CESU, por el cual se subroga el Acuerdo 001 de 2000 del Consejo Nacional de Educación Superior, CESU, y con el cual se expide el reglamento, se determina la integración y las funciones del Consejo Nacional de Acreditación.

Resolución № 000167 del 31 de Mayo de 2006 - Icfes, por la cual se formaliza una delegación.

Resolución $N^{\circ} 183$ de febrero 2 de 2004, por la cual se define la organización de la Comisión Nacional Intersectorial de Aseguramiento de la Calidad de la Educación Superior, CONACES.

Decreto 4675 de 2006. Por el cual se Modifica la Estructura del Ministerio de Educación Nacional

Decreto 4674 de 2006. Por el cual se modifica la Planta Global del Ministerio de Educación Nacional

Decreto 4729 de 2007. Por el cual se otorga la Orden a la Educación Superior y a la Fe Pública "Luis López de Mesa".

Decreto 128 de enero 26 de 1976. Por el cual se dicta el estatuto de inhabilidades, incompatibilidades y responsabilidades de los miembros de las juntas directivas de las entidades descentralizadas y de los representantes legales de estas.

Ley 1286 de 2009: "Por la cual se modifica la ley 29 de 1990, se transforma a Colciencias en departamento administrativo, se fortalece el sistema nacional de ciencia, tecnología e innovación en Colombia y se dictan otras disposiciones". 
Ley 29 de 1990: "Por la cual se dictan disposiciones para el fomento de la investigación científica y el desarrollo tecnológico y se otorgan facultades extraordinarias". 